\title{
Hubungan Jenis Persalinan dan Prematuritas dengan Hiperbilirubinemia di RS Persahabatan
}

\author{
Elsa Roselina $^{1 *}$, Saroha Pinem ${ }^{2 *}$, \& Rochimah ${ }^{2 *}$ \\ ${ }^{1}$ Dosen Program Studi Perumahsakitan Vokasi UI \\ ${ }^{2}$ Dosen Jurusan Keperawatan Poltekkes Kemenkes Jakarta III
}

\begin{abstract}
ABSTRAK. Hiperbilirubinemia merujuk pada akumulasi bilirubin secara berlebihan dalam darah yang dikarakteristikkan dengan jaundice atau ikterus, dimana warna kulit dan organ-organ lain menjadi menguning. Terdapat dua faktor risiko yang berhubungan dengan hiperbilirubinemia, yaitu faktor maternal dan neonatus. Penelitian ini bertujuan untuk diketahuinya variabel mana dari faktor maternal dan faktor neonatus yang berhubungan dengan hiperbilirubinemia di RS Persahabatan. Penelitian ini menggunakan rekam medik yang berjumlah 216 rekam medik ibu beserta bayinya. Sampel penelitian diambil dari bulan Oktober 2008 sampai dengan bulan Oktober 2009. Desain penelitian ini adalah kasus kontrol dengan tingkat signifikansi 5\% dan kekuatan uji $80 \%$. Analisis statistik yang digunakan adalah regresi logistik ganda. Hasil penelitian menunjukkan bahwa faktor yang berhubungan dengan hiperbilirubinemia di RS Persahabatan adalah jenis persalinan (nilai $\mathrm{p}$ 0,000) dan prematuritas (nilai p 0,022). Jenis persalinan merupakan variabel dominan yang berhubungan dengan hiperbilirubinemia dan neonatus yang lahir dari jenis persalinan yang tidak spontan memiliki peluang mengalami hiperbilirubinemia 50,193 kali dibandingkan dengan neonatus yang lahir melalui persalinan spontan setelah dikontrol oleh prematuritas (nilai OR 50,193).

Kata kunci: hiperbilirubinemia, jenis persalinan, prematuritas
\end{abstract}

ABSTRACT. Hyperbilirubinemia refers to an excessive level of accumulated bilirubin in the blood and is characterized by jaundice, or icterus, a yellowish discoloration of the skin and other organs. There are two risk factors that related to hyperbilirubinemia. Those factors are maternal factor and neonates' factor. The aim of this research knew which variables which catagorized as maternal factor and neonates' factor that related to hyperbilirubinemia in Persahabatan hospital. This research used medical records from 216 neonates and his/her mother from October 2008 until October 2009 as samples. Research design was case control, with used $5 \%$ level of significant and $80 \%$ power. The statistical analysis was multivariable logistic regression. Factors that related to hyperbilirubinemia in Persahabatan hospital were type of labor ( $p$ value 0.000 ) and prematurity ( $p$ value 0.022). Type of labor is a dominant variable that related to hyperbilirubinemia and neonates from un-spontaneous labor has probability to be hyperbilirubinemia 50.193 times than neonates from spontaneous labor after controlled by prematurity (odds ratio 50.193).

Keywords: hyperbilirubinemia, type of labor, prematurity 


\section{PENDAHULUAN}

\section{Latar Belakang}

Hiperbilirubinemia adalah akumulasi bilirubin secara berlebihan dalam darah yang dikarakteristikkan dengan jaundice atau ikterus, dimana warna kulit dan organ-organ lain menjadi menguning (Hockenberry dan Wilson, 2007:317). Hiperbilirubinemia dapat menyebabkan terjadinya kerusakan neurologis, kehilangan pendengaran bahkan kejang dan kematian (Way, 2007).

Porter dan Dennis (2002) menyatakan bahwa secara umum terdapat dua faktor risiko terjadinya hiperbilirubinemia neonatus, yaitu faktor maternal dan faktor neonatus. Faktor maternal terdiri dari (1) golongan darah ABO atau inkompatibilitas Rh, (2) pemberian ASI, (3) penggunaan obat (diazepam atau oxytocin), (4) etnis dan (5) penyakit maternal: diabetes gestasional. Adapun Faktor neonatus terdiri dari (1) trauma saat lahir (termasuk melahirkan dengan penggunaan alat), (2) obat: Sulfisoxazole acetyl dengan Erythromycin ethylsuccinate (Pediazole), Chloramphenicol (Chloromycetin), penurunan berat badan neonatus secara berlebihan setelah lahir, (4) infeksi: TORCH, (5) jarang menyusu, (5) jenis kelamin laki-laki, (6) Prematuritas dan (7) riwayat anak sebelumnya dengan hiperbilirubinemia.

Berdasarkan hasil studi pendahuluan di RS Persahabatan yang didapatkan melalui data rekam medis dari bulan Agustus sampai Oktober 2009, proporsi kejadian hiperbilirubinemia adalah 15,64\% (79 dari 505 kelahiran), dimana dari proporsi tersebut kejadian hiperbilirubinemia pada neonatus yang lahir dengan vakum paling tinggi yaitu 43\% (11 dari 32 persalinan). Sisanya diikuti oleh neonatus yang lahir dengan sectio caesaria yaitu 24\% (37 dari 156 persalinan) dan neonatus yang lahir dengan spontan yaitu 10\% (31 dari 317 persalinan).

\section{Pokok Masalah}

Proporsi kejadian hiperbilirubinemia di RS Persahabatan cukup besar dimana proporsi terendah berasal dari neonatus yang lahir dari persalinan spontan. Penelitian serupa belum pernah dilakukan di RS Persahabatan.

\section{Tujuan Penelitian}

Penelitian ini bertujuan untuk: diketahuinya variabel apa dari faktor maternal dan neonatus yang berhubungan dengan hiperbilirubinemia di RS Persahabatan, dan (2) diketahuinya variabel yang paling dominan terhadap hiperbilirubinemia di RS Persahabatan.

\section{METODE PENELITIAN}

Desain penelitian ini adalah kasus kontrol. Populasi adalah neonatus bersama ibu yang melahirkannya di RS Persahabatan. Sampel adalah 216 orang neonatus bersama ibu yang melahirkannya di RS Persahabatan dari Oktober 2008 sampai Oktober 2009. Penelitian menggunakan sumber data sekunder (rekam medik) dengan tehnik pengumpulan secara simple random sampling. Nilai alpha yang digunakan dalam penelitian ini $5 \%$ dengan kekuatan uji $80 \%$. Analisis statistik yang digunakan adalah univariabel, 
bivariabel (uji kai kuadrat) dan multivariabel

(uji regresi logistik ganda).

\section{ANALISIS DAN PEMBAHASAN}

\section{Analisis Univariabel}

Mayoritas ibu tidak mendapatkan induksi oksitosin sebelum persalinan yaitu sebanyak 146 orang (67,6\%). Mayoritas ibu melahirkan secara spontan yaitu sebanyak 149 orang (69\%).
Neonatus yang lahir kebanyakan berjenis kelamin laki-laki sebanyak 109 orang (50,50\%). Mayoritas lahir dalam kondisi tidak prematur yaitu sebanyak 203 orang (94\%). Neonatus yang mengalami hiperbilirubinemia dan tidak masingmasing berjumlah 108 orang.

Hasil analisis univariabel dapat dilihat pada tabel 1 dan 2 .

Tabel 1.

Karakteristik responden berdasarkan faktor ibu di RS Persahabatan dari Oktober 2008 sampai Oktober $2009(n=216)$

\begin{tabular}{cccc}
\hline No & Faktor Ibu & Jumlah & Persentase \\
\hline 1. & Induksi oksitosin & & \\
& Tidak & 146 & 67,6 \\
& Ya & 70 & 32,4 \\
2. & Jenis persalinan & & \\
$\quad$ Spontan & 149 & 69,0 \\
& Tidak spontan: & 52 & \\
& Sectio caesaria & 11 & 24,1 \\
& Ekstraksi vakum & 4 & 5,0 \\
& Forcep & & 1,9 \\
\hline
\end{tabular}

Tabel 2.

Karakteristik responden berdasarkan faktor neonatus di RS Persahabatan dari Oktober 2008 sampai Oktober $2009(n=216)$

\begin{tabular}{cccc}
\hline No & Faktor Neonatus & Jumlah & Persentase \\
\hline 1. & Jenis kelamin & & \\
$\quad$ Laki-laki & 109 & 50,5 \\
$\quad$ Perempuan & 107 & 49,5 \\
2. & Prematuritas & & \\
$\quad$ Tidak & 203 & 94,0 \\
$\quad$ Ya & 13 & 6,0 \\
3. $\quad$ Hiperbilirubinemia & 108 & 50,0 \\
$\quad$ Tidak & 108 & 50,0 \\
$\quad$ Ya & & \\
\hline
\end{tabular}

\section{Analisis Bivariabel}

Hasil uji kai kuadrat memperlihatkan adanya hubungan antara jenis persalinan dan prematuritas dengan hiperbilirubinemia.

Berdasarkan hasil analisis hubungan antara jenis persalinan dengan 
hiperbilirubinemia diperoleh bahwa terdapat perbedaan proporsi antara responden dengan jenis persalinan tidak spontan (sectio caesaria, ekstraksi vakum, forcep) dengan responden yang mengalami persalinan spontan terhadap hiperbilirubinemia. Hasil uji statistik menunjukkan adanya hubungan yang bermakna antara jenis persalinan dengan hiperbilirubinemia (nilai p 0,000). Hasil analisis juga memperlihatkan bahwa ibu dengan jenis persalinan tidak spontan memiliki peluang 50,909 kali bayinya mengalami hiperbilirubinemia dibandingkan dengan ibu dengan jenis persalinan spontan.

Demikian juga halnya dengan hasil analisis hubungan antara prematuritas dengan hiperbilirubinemia, dimana terdapat perbedaan proporsi antara responden yang mengalami prematuritas dengan responden yang tidak mengalami prematuritas terhadap hiperbilirubinemia. Hasil uji statistik menunjukkan adanya hubungan yang bermakna antara prematuritas dengan hiperbilirubinemia (nilai p 0,022). Hasil analisis juga memperlihatkan bahwa bayi yang lahir dalam kondisi prematur berpeluang 6,010 kali mengalami hiperbilirubinemia dibandingkan dengan bayi yang lahir tidak dalam kondisi prematur.

Hal ini dapat dilihat pada tabel 3.

Tabel 3. Distribusi responden di RS Persahabatan dari Oktober 2008 sampai Oktober 2009

\begin{tabular}{|c|c|c|c|c|c|c|c|c|c|}
\hline \multirow{3}{*}{ No } & \multirow{3}{*}{ Variabel } & \multicolumn{4}{|c|}{ Hiperbilirubinemia } & \multirow{2}{*}{\multicolumn{2}{|c|}{ Jumlah }} & \multirow{3}{*}{$\begin{array}{c}\text { OR } \\
95 \% \mathrm{CI}\end{array}$} & \multirow{3}{*}{ Nilai $p$} \\
\hline & & \multicolumn{2}{|c|}{$\begin{array}{c}\text { Tidak } \\
(n=108)\end{array}$} & \multicolumn{2}{|c|}{$\begin{array}{c}\text { Ya } \\
(n=108)\end{array}$} & & & & \\
\hline & & $n$ & $\%$ & $n$ & $\%$ & $\mathbf{N}$ & $\%$ & & \\
\hline 1. & Induksi oksitosin & & & & & & & & \\
\hline & Tidak & 2 & 49,3 & 74 & 50,7 & 146 & 100 & $\begin{array}{c}0,919 \\
0,520-1,625\end{array}$ & 0,884 \\
\hline & $\begin{array}{l}\text { Ya } \\
\text { Yonicolinon }\end{array}$ & 36 & 51,4 & 34 & 48,6 & 70 & 100 & & \\
\hline 2. & $\begin{array}{l}\text { Jenis persalinan } \\
\text { Spontan }\end{array}$ & 105 & 70,5 & 44 & 29,5 & 149 & 100 & $\begin{array}{c}50,909 \\
15,179-170,744\end{array}$ & $0,000^{*}$ \\
\hline 3. & $\begin{array}{l}\text { Tidak spontan } \\
\text { Jenis kelamin }\end{array}$ & 3 & 4,5 & 64 & 95,5 & 67 & 100 & & \\
\hline & Perempuan & 58 & 54,2 & 49 & 45,8 & 107 & 100 & $\begin{array}{c}1,397 \\
0,818-2,386\end{array}$ & 0,276 \\
\hline 4. & $\begin{array}{c}\text { Laki-laki } \\
\text { Prematuritas }\end{array}$ & 50 & 45,9 & 59 & 54,1 & 109 & 100 & & \\
\hline & Tidak & 106 & 52,2 & 97 & 47,8 & 203 & 100 & $\begin{array}{c}6,010 \\
1,299-27,801\end{array}$ & $0,022^{*}$ \\
\hline & $\mathrm{Ya}$ & 2 & 15,4 & 11 & 84,6 & 13 & 100 & & \\
\hline
\end{tabular}

* hubungan bermakna 
Hubungan jenis persalinan sectio caesaria dengan hiperbilirubinemia dipersepsikan oleh peneliti memiliki hubungan yang tidak langsung, dimana persalinan sectio caesaria akan menunda ibu untuk menyusui bayinya, yang kemudian dapat berdampak pada lambatnya pemecahan kadar bilirubin. Hal ini sesuai dengan pernyataan Dewey et.al (2003) bahwa salah satu faktor yang berhubungan dengan penundaan menyusui bayi oleh ibu segera setelah melahirkan adalah ibu yang melahirkan dengan operasi sectio caesaria. Kearnay dalam Roirdan dan Auerbach (1998) juga memberikan penjelasan yang logis terkait dengan hal ini, bahwa ibu yang melahirkan dengan operasi sectio caesaria membutuhkan waktu yang lebih lama untuk pemulihan kesehatannya dan adanya tingkat rasa sakit yang lebih tinggi dibandingkan dengan ibu yang melahirkan per vaginam (spontan), sehingga pemberian ASI kepada bayi akan tertunda. Hasil penelitian Gustina, Ismail dan Roselina (2008) juga menunjukkan adanya hubungan yang bermakna antara jenis persalinan dengan perilaku pemberian kolostrum (nilai p 0,044), dimana ibu dengan jenis persalinan operasi sectio caesaria memiliki peluang 2,37 kali untuk memberikan ASI kolostrum setelah 24 jam persalinan dibandingkan dengan ibu dengan jenis persalinan normal (nilai OR 2,37).

Hubungan prematuritas dengan hiperbilirubinemia sejalan dengan apa yang dinyatakan White (2005:188), dimana hiperbilirubinemia berkembang selama 5 hari pertama kehidupan bayi, terjadi pada $80 \%$ neonatus yang prematur dan $45 \%$ sampai $60 \%$ pada neonatus yang matur. Hal ini pun sejalan dengan kondisi fisiologis organ hati pada neonatus yang rentan mengalami hiperbilirubinemia. Kondisi ini disebabkan oleh organ hati neonatus yang memiliki kandungan hepatosit $20 \%$ lebih sedikit dari organ hati dewasa, juga berkurangnya enzim glukoronil transferase yang berperan pada peristiwa pembentukan bilirubin tak terkonjugasi menjadi bilirubin terkonjugasi yang mengakibatkan masih tingginya kadar bilirubin tak terkonjugasi dalam darah (Wong, et.al, 2009). Fungsi hati yang immatur pada neonatus prematur lah yang memperberat risiko mengapa neonatus prematur lebih sering mengalami hiperbilirubinemia dibandingkan dengan neonatus yang matur.

\section{Analisis Multivariabel}

Hasil akhir analisis regresi logistik ganda dapat dilihat pada tabel 4. Tabel tersebut memperlihatkan bahwa jenis persalinan merupakan variabel yang paling dominan berhubungan dengan hiperbilirubinemia, dimana neonatus yang lahir dengan jenis persalinan tidak spontan berpeluang mengalami hiperbilirubinemia 50,193 kali dibandingkan dengan yang lahir secara spontan setelah dikontrol prematuritas. 
Hubungan Jenis Persalinan dan Prematuritas dengan Hiperbilirubinemia di RS Persahabatan

Elsa R., Saroha P., Rochimah

Volume I, Nomar I, pp 74-81 
Tabel 4.

Model akhir analisis regresi logistik ganda

\begin{tabular}{lrrr}
\hline \multicolumn{1}{c}{ Model } & B & P Wald & OR \\
\hline Hiperbilirubinemia dengan jenis persalinan dan prematuritas & & & \\
pada: & & & \\
jenis persalinan & 3,916 & 0,000 & 50,193 \\
prematuritas & 1,691 & 0,052 & 5,425 \\
konstanta & $-0,948$ & 0,000 & 0,387 \\
\hline
\end{tabular}

Berdasarkan tabel 4, model regresi logistik ganda yang dihasilkan adalah:

Logit (hiperbilirubinemia) $=-0,948+$ 1,691 prematuritas $+3,916$ jenis persalinan.

Model regresi logistik ganda tersebut akan digunakan dalam menentukan peluang hiperbilirubinemia yang dihitung dengan persamaan:

$$
\mathrm{P}=\frac{1}{1+\mathrm{e}^{- \text {Logit (hiperbilirubinemia) }}}
$$

Hal ini berarti bahwa peluang hiperbilirubinemia pada neonatus berbedabeda sesuai dengan kondisi responden, yaitu:

1. Ibu dengan jenis persalinan tidak spontan dan bayi yang dilahirkannya prematur

Nilai Logit (hiperbilirubinemia) = $0,948+1,691^{*} 1+3,916^{*} 1=4,659$

$$
\text { Nilai } \mathrm{P}=\frac{1=0,99}{1+\mathrm{e}^{-4,659}}
$$

Artinya: Peluang seorang bayi akan mengalami hiperbilirubinemia jika ibunya mengalami jenis persalinan tidak spontan dan bayi tersebut dilahirkan dalam kondisi prematur adalah sebesar $99 \%$.
2. Ibu dengan jenis persalinan tidak spontan dan bayi yang dilahirkannya tidak prematur

Nilai Logit (hiperbilirubinemia) = $0,948+1,691 * \mathrm{O}+3,916^{*} 1=2,968$

Nilai $\mathrm{P}=1=0,95$

$$
1+\mathrm{e}^{-2,968}
$$

Artinya: Peluang seorang bayi akan mengalami hiperbilirubinemia jika ibunya mengalami jenis persalinan tidak spontan dan bayi tersebut dilahirkan dalam kondisi tidak prematur adalah sebesar $95 \%$.

3. Ibu dengan jenis persalinan spontan dan bayi yang dilahirkannya prematur Nilai Logit (hiperbilirubinemia) = $0,948+1,691^{*} 1+3,916^{*} \mathrm{O}=0,743$

$$
\text { Nilai } P=\frac{1=0,68}{1+\mathrm{e}^{-0,743}}
$$

Artinya: Peluang seorang bayi akan mengalami hiperbilirubinemia jika ibunya mengalami jenis persalinan spontan dan bayi tersebut dilahirkan dalam kondisi prematur adalah sebesar $68 \%$.

4. Ibu dengan jenis persalinan spontan dan bayi yang dilahirkannya tidak prematur

Nilai Logit (hiperbilirubinemia) = $0,948+1,691 * \mathrm{O}+3,916^{*} \mathrm{O}=-0,948$ 
Nilai $\mathrm{P}=1=\frac{0,28}{1+\mathrm{e}^{0,948}}$

Artinya: Peluang seorang bayi akan mengalami hiperbilirubinemia jika ibunya mengalami jenis persalinan spontan dan bayi tersebut dilahirkan dalam kondisi tidak prematur adalah sebesar $28 \%$.

\section{KESIMPULAN}

Berdasarkan hasil penelitian yang telah dilakukan, dapatlah disimpulkan bahwa terdapat hubungan antara jenis persalinan dan prematuritas dengan hiperbilirubinemia. Jenis persalinan merupakan variabel yang paling dominan, dimana neonatus yang lahir dengan jenis persalinan tidak spontan berpeluang untuk mengalami hiperbilirubinemia 50,193 kali dibandingkan dengan yang lahir secara spontan setelah dikontrol prematuritas (nilai OR 50,193). Nilai peluang terjadinya hiperbilirubinemia pada neonatus pun berbeda-beda sesuai dengan kondisi ibu dan bayi, dimana peluang seorang bayi akan mengalami hiperbilirubinemia paling besar jika ibunya mengalami jenis persalinan tidak spontan dan bayi tersebut dilahirkan dalam kondisi prematur, yaitu sebesar 99\%.

\section{DAFTAR PUSTAKA}

Dewey, et al. 2003. Risk Factors for Suboptimal Infant Breat Feeding Behaviour, Delay Onset of Lactation, and excess Neonatal Weight Loss. Pediatrics. Vol. 112. No. 3. September 2003. pp 607-619

Gustina, Ismail R. dan Roselina, E. 2008. Faktor-faktor yang Berhubungan dengan Perilaku Pemberian Kolostrum pada Ibu Post Partum di RS Persahabatan. Jurnal MADYA. Vol. 4, No. 1, Juni 2008.

Hockenberry, M.J. dan Wilson, D. 2007. Wong's: Nursing care of infants and children, $8^{\text {th }}$ ed. St. Louis: Mosby Elsevier.

Porter dan Dennis. 2002. Hyperbilirubinemia in the term newborn. http://www.aafp.org/afp/200202 15/599.pdf. Diunduh tanggal 16 Oktober 2009.

Riordan, J. dan Auerbach, K. 1998. Breastfeeding and human lactation. Jones and Bartlett Publishers, Toronto.

Way, K. 2007. Jaundice in newborns. http://www.childbirthsolutions.com/ articles/postpartum/jaundice/index.php. Diunduh tanggal 19 September 2007.

White, L. 2005. Foundation of maternal and pediatric nursing, $2^{\text {nd }}$ ed. New York: Thomson Delmar Learning.

Wong, D. L. et. al. 2009. Wong's essentials of pediatric nursing, $6^{\text {th }}$ ed. Missouri: Mosby. 